Austria should invest in brains, not in bricks, banks or airlines

SIR - Because of uncertainty about this year's science budget, as expressed in your News in Brief story 'Austrian scientists rattled by threat to funding' (Nature 457, 648; 2009), the Austrian science fund FWF has postponed its first two board meetings of 2009. It has frozen all decisions on already-reviewed grant applications until May 2009. As the FWF is by far the most significant public agency supporting basic research in Austria, any reduction of its moderate budget would be a devastating blow.

This uncertainty puts the Austrian government's recent efforts to advance science, and to attract internationally renowned scientists, into serious jeopardy. Because the basic subsidy for universities is low, scientists have been relying heavily on competitive funding from the FWF.

We find it obscene that the government is pursuing its plan to establish an 'elite university' near Vienna - the Institute of Science and Technology Austria - while competitive funding is at risk. Do the institute's newly appointed president and his senior academic staff know that one crucial pillar of their budget is cracking? Do our gifted young students preparing for an academic career recognize that, without funding by the FWF, the academic world is at risk? Do their parents know that their children are heading down a blind alley?

We hope that our officials consider what is best for the future of the country: invest in brains - not bricks, banks or airlines. Knowing what technology means for a country, the US National Institutes of Health has just received additional funding of $\$ 10.4$ billion. Perhaps Austrian students and scientists will again have to go west to the United States to survive the current global economic crisis.

Michael Freissmuth Department of

Pharmacology, Medical University of Vienna, Währingerstrasse 13A, 1090 Vienna, Austria

e-mail: michael.freissmuth@

meduniwien.ac.at

Sigismund Huck Center for Brain

Research, Medical University of

Vienna, Spitalgasse 4,

1090 Vienna, Austria

\section{Evolution and intelligent design in Hong Kong}

SIR - Your News story 'Hong

Kong evolution curriculum row'

(Nature 457, 1067; 2009) reports

a call by faculty members at Hong

Kong University for a sentence to

be removed from new guidelines

for secondary-school biology

education. At present, these state:

"In addition to Darwin's theory,

students are encouraged to

explore other explanations for

evolution and the origins of life, to

help illustrate the dynamic nature of scientific knowledge". You also note that a professor criticized the university for not letting him teach intelligent design in his course on the origin of the Universe.

I was born in Hong Kong, was educated at local missionary schools and Hong Kong University, and am now overseas doing research in the field of evolution and development. As a scientist, I believe that the purpose of education is not only to pass knowledge to future generations, but also to develop students' analytical and critical thinking. Central to both aspects is the need to focus on facts and testable views supported by evidence. This is all the more important given the limited amount of time available for teaching and its support by public funding. Evolution fulfils these necessary criteria, whereas intelligent design, being untestable and unsupported by evidence, does not.

Hong Kong is a multicultural society, deeply imprinted with traditional Chinese culture and values, but also facing a constant inrush of ideas from the West. The fundamental cause of these controversies is more than just a cultural clash. It reflects a lack of long-term public education in evolutionary biology. In the year of Darwin 200, it is time to rectify this situation.

Jerome H. L. Hui Faculty of Life Sciences, University of Manchester, Michael Smith Building,

Manchester M13 9PT, UK

e-mail: jerome.hui@manchester.ac.uk

\section{Scientists must stand up and be counted}

SIR - In your Editorial 'Against vicious activism' (Nature 457, 636; 2009), you call for scientists and the authorities to stand up for animal research in basic and applied science. However, you may be putting the cart before the horse in recommending that officials and politicians become advocates of animal research in order to encourage individual scientists to do so.

In the United Kingdom, it was the actions of individual scientists - and of members of the public who joined the ProTest demonstration in Oxford in February 2006 and signed the Coalition for Medical Progress's petition - that gave politicians and other public figures the encouragement they needed to come out in support of animal research. The lesson to be learned from the UK experience is that scientists at the universities being targeted by extremists, alongside students and advocacy groups, must be encouraged to stand up and be counted. Only then can they expect others less directly involved to take an unequivocal public stand.

A parallel could be drawn with the debate over the use of embryonic stem cells for research in the United States, where support among the general public and in Congress has been driven by the strong vocal endorsement of individual scientists and advocacy groups.

The truth, uncomfortable though it may be, is that - as with many controversial areas of science - those working with animals in research must make a public case to justify their use, and must be willing to show unequivocal support for colleagues who speak up. Do that, and the rest will follow.

Dave Bienus Speaking of Research, and Pennsylvania State University, 101 Centralized Biological Laboratory, University Park, Pennsylvania 16802, USA e-mail:dab43@psu.edu

\section{Animal-health facility in Germany leads the way for Europe}

SIR - Your News story 'Britain hits a hurdle in replacing key animal-pathogen facility' (Nature 457, 769; 2009) describes the problems faced by the Institute for Animal Health in Pirbright. It is deplorable that this world-class institute is uncertain of being able to develop a key animalpathogen facility and other adequate infrastructure.

In contrast, Germany's federal ministry of food, agriculture and consumer protection is investing nearly €300 million (US\$395 million) to create a state-of-theart facility for infectious-disease research at our institute on the Isle of Riems in the Baltic Sea. New laboratory and animal facilities will be constructed, including a biosafety-level-4 facility for large animals that is unique in Europe. The plans were developed in the mid-1990s and construction should be largely finished in time for the institute's centenary in late 2010.

Thomas C. Mettenleiter FriedrichLoeffler-Institut, Federal Research Institute for Animal Health, Südufer 10, 17493 Greifswald-Insel Riems, Germany e-mail: thomas.mettenleiter@ fli.bund.de 